\title{
Hyaluronic acid injection procedures and orthodontic practice
}

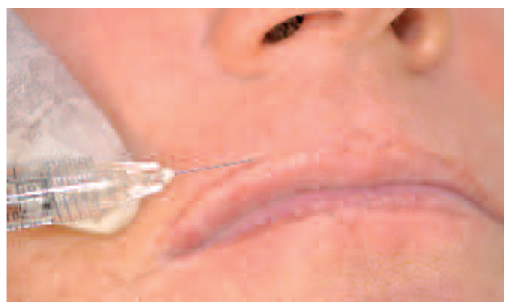

\author{
Jean-Pierre SALAMA
}

\section{ABSTRACT}

In France, the Public Health Code was amended in 2004, and now allows dentists to treat facial tissues adjacent to the mouth: and hence, they can now bridge the gap between maxillary sinuses and the mouth area by performing hyaluronic acid injection procedures in the perio-buccal soft tissues.

Accordingly, the National Council of the Order of Dental Surgeons authorizes the practice of hyaluronic acid injection for therapeutic use.

In this article, we will define the legal framework for which we will be held liable as it pertains to hyaluronic acid injection procedures.

After explaining the physico-chemical properties of hyaluronic acid, we will study the mechanisms of ageing, the architecture of the face and various methods of injection.

We will look at the indications and counter indications for the use of hyaluronic acid injection, particularly in terms of its therapeutic usefulness for rehabilitating soft tissue when transitioning from a maxillary full-arch prosthesis to an implant born bridge.

Hyaluronic acid makes it possible to offset the lack of buccal margin of the resin-based removable prosthesis.

\section{KEY WORDS}

Hyaluronic acid,

Naso-labial folds,

Cannula,

Reticulation. 


\section{1 - INTRODUCTION}

Over the last 10 years, dentists have noticed an increasing number of patients seeking consultation for reasons other than dental discomfort.

Presently, because of the evolution of new technologies and the improvement of dental instruments, dentists can change the color of teeth, modify their position and appearance with veneers, and realign teeth, without bonding brackets by using transparent splints such as the Invisalign technique.

\section{2 - LEGITIMIZATION}

The main priority of our patients is to improve their smiles.

However, the smile is not just limited to the teeth, it also includes the appearance of the lips that cover the teeth, the naso-labial folds that surround them, the presence or not of epidermal and dermal breakage around the mouth and, marionette lines or oral commissures.

The appearance of the tissue adjacent to the mouth is key to the successful completion of our dental procedures for restoration and enhancement. Therefore, dentists have a legitimate claim for treating tissue surrounding the mouth because the right to include hyaluronic acid injections into our practice has been legislated and approved and is no longer a matter of debate.

In fact, the amendment of the Public Health Code signed into law on August 9, 2004 concerning den-
Finally, it is important to differentiate between skin-filling molecules or fillers and botox (botulinum toxin). These are two totally different procedures and our patients often confuse one with the other.

As for fillers, dentists can literally fill dermal breakdown with hyaluronic acid.

In the case of botox, only plastic surgeons or maxillo-facial surgeons, dermatologists or ophthamologists can use toxin to block the signal of the nerve to the muscle.

tists, specifies that treatment of tissue adjacent to the mouth clearly falls within their area of expertise.

After giving us permission to set up a website and to use MEOPA (oxygen and nitrous oxide mixtures) at the chair, the National Council of the Order of Dental Surgeons published on its site: "We are eminently qualified to administer hyaluronic acid injections".

On February 14, 2012, the secretary of the Minister of Health, Xavier Bertrand, during an interview with Christian Couzinou, president of the National Council of the Order of Surgical Dentists, concluded that hyaluronic acid injections in the naso-labial folds as well as in perio-buccal area were in complete harmony with the professional training of dentists.

Accordingly insurance companies now insure dentists for this type of procedure. 


\section{3 - LEGISLATION}

When the purpose of a procedure is to repair a morphological anomaly, dentists are legally obliged to implement specific methods of treatment, however, the therapeutic contingency must be taken into account; there is no legal obligation to guarantee results. Strict adherence to methods of treatment involves greater accountability.

Legally, an estimate of cost must be completed and signed.

Dentists must provide individualized informed consent forms to their patients that clearly indicate all the different risks incurred by undergoing treatment with injections of hyaluronic acid. These forms should also be signed.

\section{4 - SOME HISTORY}

\section{$4-1$ What is hyaluronic acid?}

Much like the history of trying to bridge the gap between maxillary sinuses and the mouth area, the process leading up to the use of hyaluronic acid by dentists has been long and arduous. Initially, during facelift procedures, plastic surgeons used autologic fillers made from the fat of the patient to fill wrinkles, much as dentists used autologic bone (especially from the iliac crest and the ramus) to fill the maxillary sinus.

Then, non-resorbable injectable fillers were used more or less successfully but some had catastrophic results. Namely, Dermalive which caused severe granulomatous reactions which were not curtailed even
Hyaluronic acid is a natural absorbable molecule; therefore, the after effects are rare and transitory, and very often just a result of the injection itself.

Before performing this procedure, dentists must certify that they are trained in this procedure and must take out a rider on their professional liability insurance policy with their insurance carrier.

Finally, to complete the patient's file, the dentist must take before and after injection photos of the patient: at rest with both full face and profile views, and while propulsing the lips and making faces in order to "pucker the lips".

with strong doses of corticosteroids. In fact, following the reactions to the non-resorbable filler and the corticosteroid therapy, corrective surgery was sometimes necessary.

Hyaluronic acid was first isolated from the vitreous fluid of a bovine eye.

The etymology of the word reminds us and means vitreous; it contains a high percentage of uronic acid.

Hyaluronic acid or sodium hyaluronate is actually a complex polysaccharide, called Glycosaminoglycane.

Hyaluronic acid is a naturally occurring substance in the human body found mainly in the joints, the placenta, the eye and the dermis. In fact, roughly $50 \%$ of the hyarlonic acid in our body is found in the skin. 


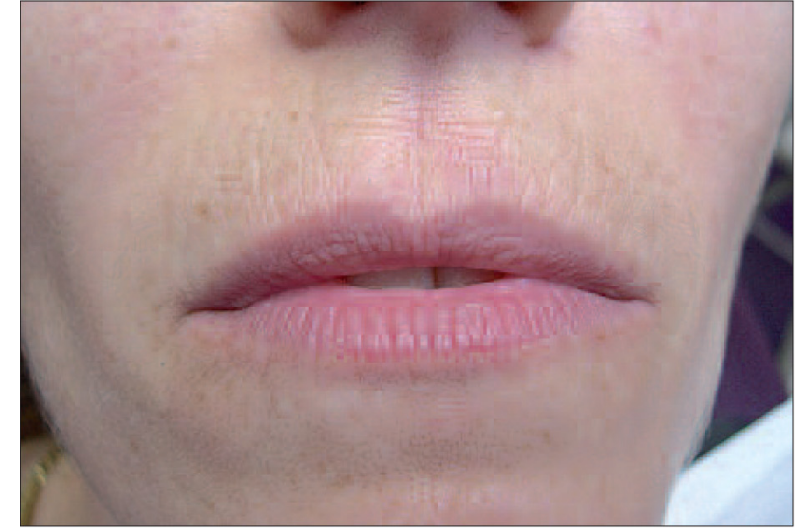

a
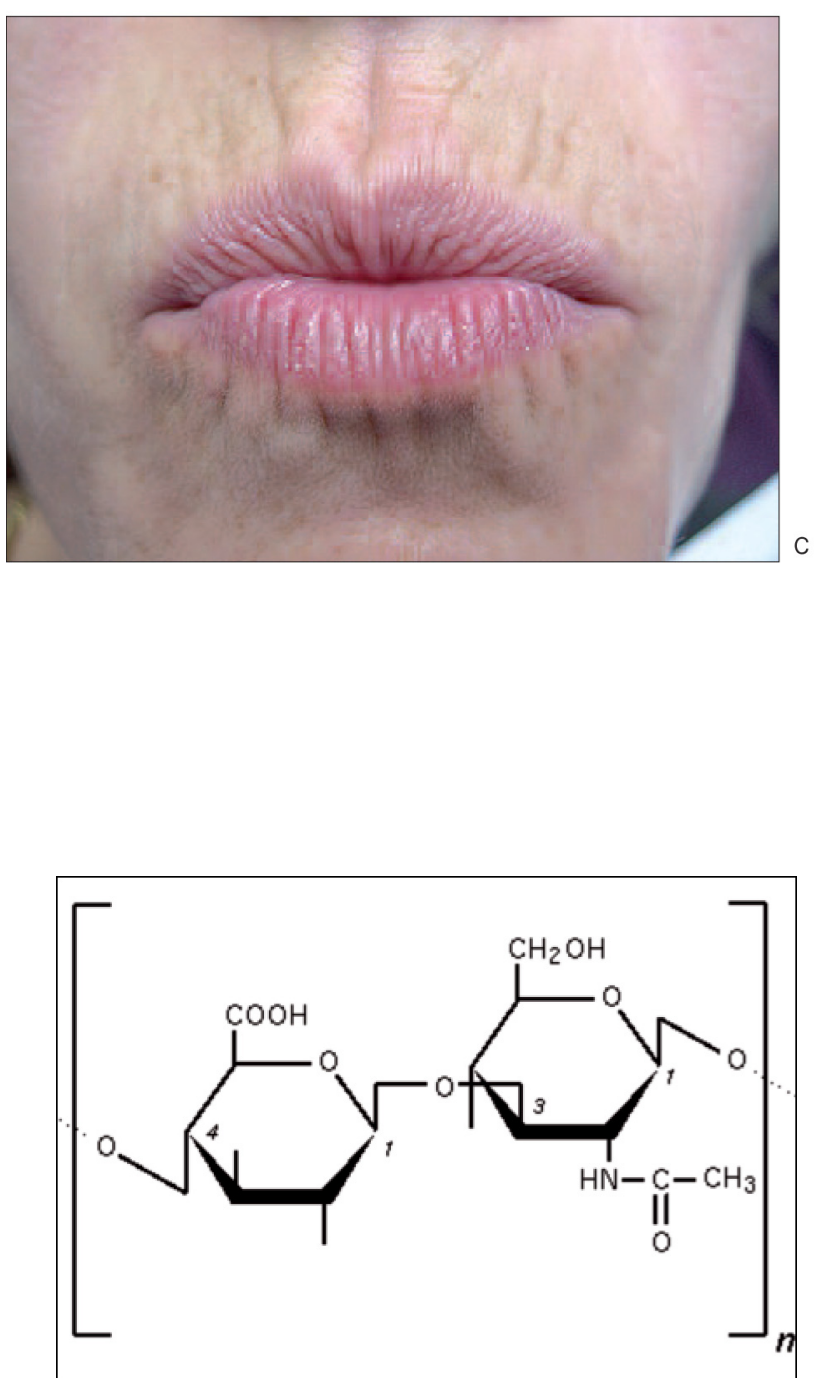

Figure 2

Hyarulonic acid formula.

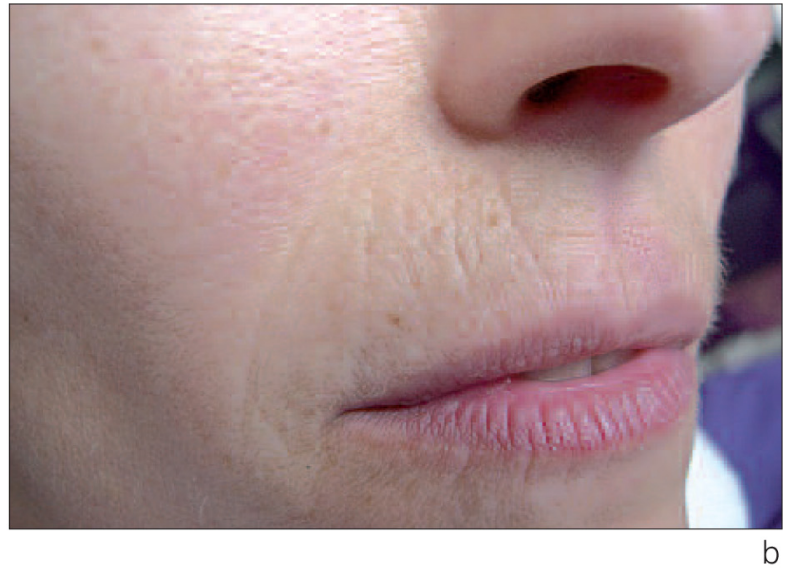

Figures 1a to $1 \mathrm{C}$

Three photos of the patient:

a. at rest

b. three quarters,

c. exaggerated puckering to sometimes reveal dermal breakage that is not visible when at rest.

Hyaluronic acid works like a sponge and can soak up moisture: each molecule can absorb from 500 to 1000 times its own weight in water.

But as the body ages, the quantity of hyaluronic acid decreases; so, surgeons came up with the idea of using it to compensate for this loss. For example, it is used in ophthalmological surgery (cornea transplants, cataracts, glaucoma, etc.) and to treat osteoarthritis of the knee. 
Cosmetically, it can be used for facelifts. This is one of the most important uses of hyaluronic acid and we will say more about this later in the article. Hyaluronic acid is a biocompatible and biodegradable substance; it is a naturally produced lubricant that is quickly absorbed: by mechanical friction in areas of the face which move or wrinkle frequently, by hyaluronidases, a family of enzymes which degrade it and, by free radicals which circulate in the body. Therefore, since it traps free radicals, hyaluronic acid has anti-oxydant properties.

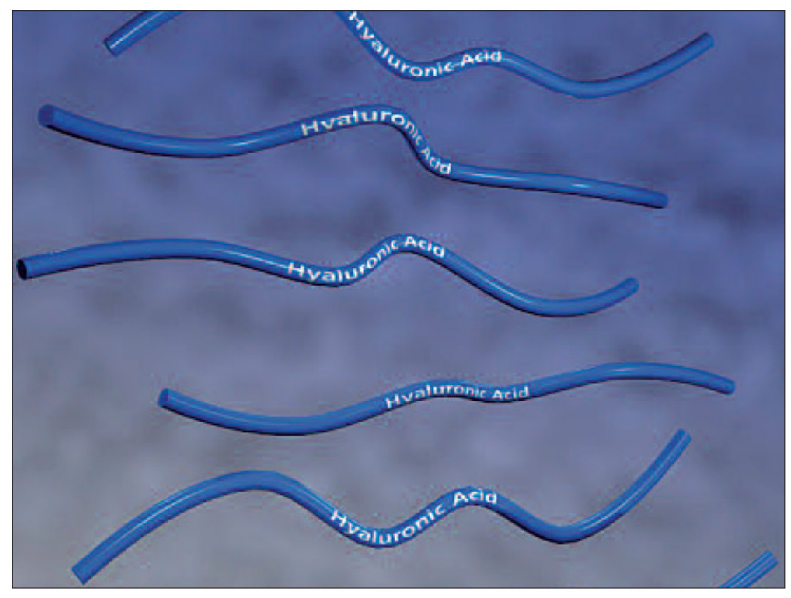

Figure 3

Free molecules of hyaluronic acid.

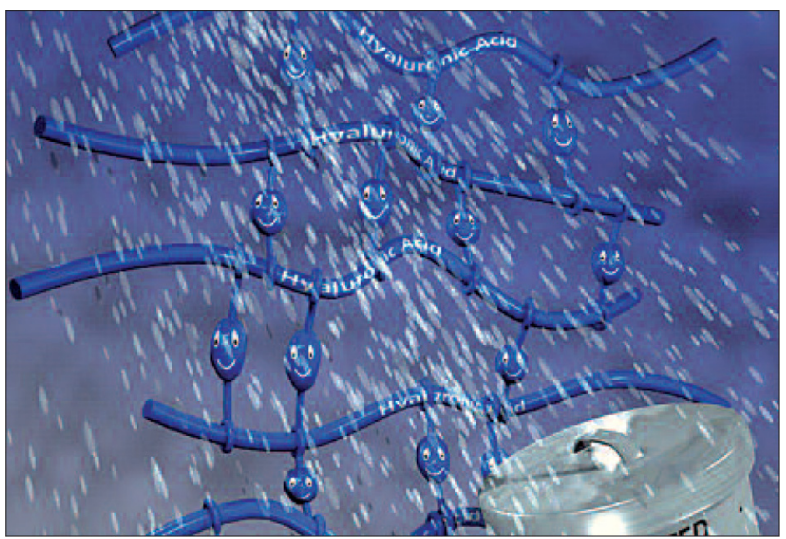

It is a non-species specific molecule and there is no difference between endogenous and exogenous molecules.

As individuals grow older, the quantity of hyaluronic acid decreases and this quantitative change triggers a qualitative deterioration of the soft tissues and also slows cellular processes to regenerate and repair.

It possesses viscoelastic properties that play an important role in strengthening the extracellular matrix and reinforcing buffering actions. All these

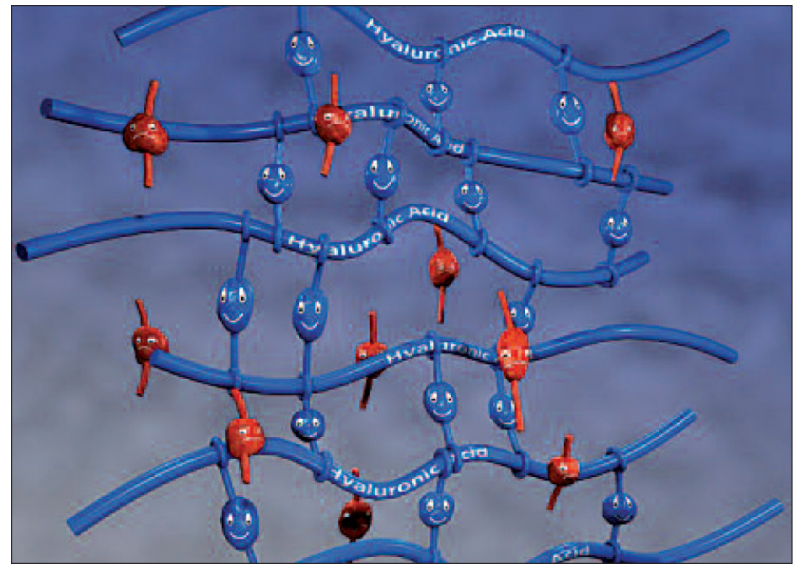

Figure 4

The reticulation takes place in a two dimension plane and a three dimension space, to obtain a tridimensional matrix which can last to up to approximately 1 year.

Figure 5

The reagent that failed to bond is eliminated.

(Photographs made available by the Laboratoire Allergan, Sophia Antipolis, Mougins.) 
rheological properties promote cellular migration and proliferation and, in doing so, facilitate the healing process. Additionally, it has an anti-aging effect, since it supports collagen synthesis, restores the integrity of fibroblasts, stimulates growth factors and inhibits the synthesis of collagenase (Wang, 2007).

This free molecule in the body has a half-life of approximately 48 hours. As a result, all the injected hyaluronic acid is completely resorbed in approximately 4 days.
The injected molecule is finally completely absorbable in 8 to 12 months, based on the area that is injected, on the blood flow and, on the degree of molecular reticulation.

That is why it was thought that we could reticulate hyaluronic acid, namely, create a bond between the molecules with a chemical reagent, in order to increase its molecular mass and limit the mechanisms of degradation.

The reagent that was used is BDDE (Butanediol Diglycidyl Ether): bonding

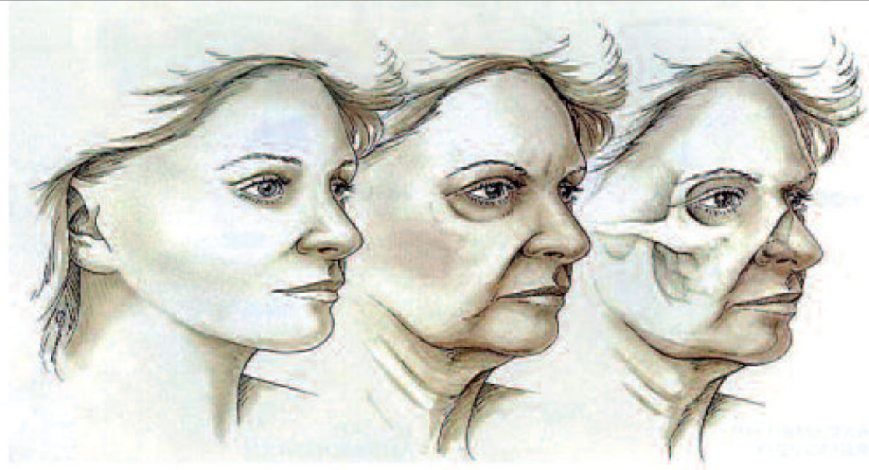

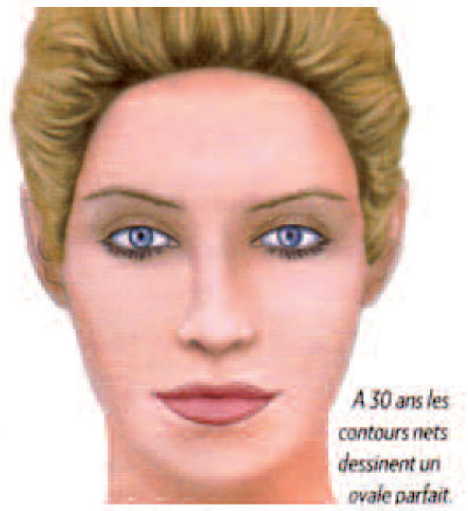

20 ans

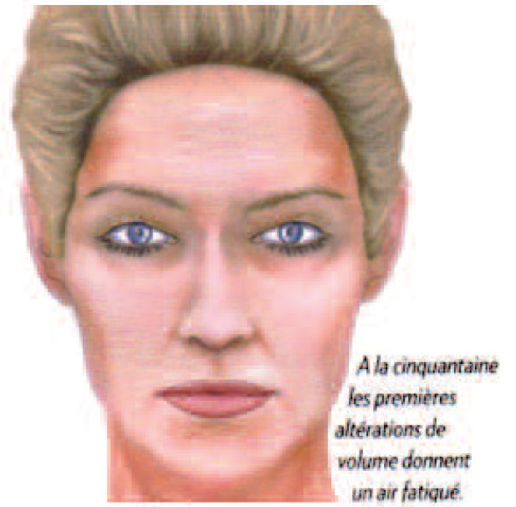

50 ans

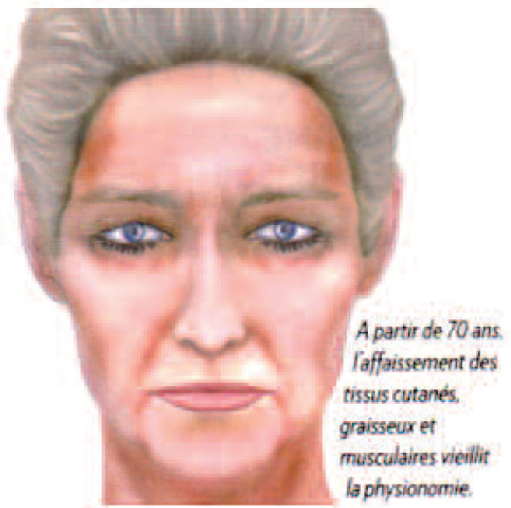

75 ans

Figure 6

A 30 year old woman has well-defined contours that form a perfect oval.

A 50 year old woman shows the first alterations in muscle volume and appears tired.

A 75 year old woman's physiognomy looks old because of sagging cutaneous, fat and muscular tissues.

Source: Coleman, Sydney R. M.D. Structural Fat Grafting. St. Louis, Mo.: Quality Medical, 2004. 
agent (molecule bonding two other molecules) chosen for its remanence and manual injectability. When exposed to hyaluronic acid, the bonding reagent crosslinks the molecules.

The more hyaluronic is reticulated, the more it becomes viscous, turning into a liquid, then a gel and finally into a solid; biological membranes made up of hyaluronic acid are in fact being studied for the purpose of Guided Bone Regeneration (GBR).

The resorption time for these membranes is approximately 8 months.

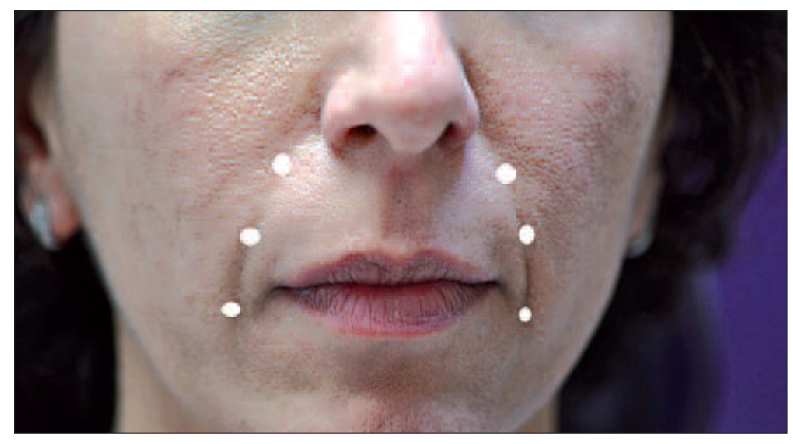

Figure 7

Needle punctures (by serial puncture) to treat the nasolabial fold.

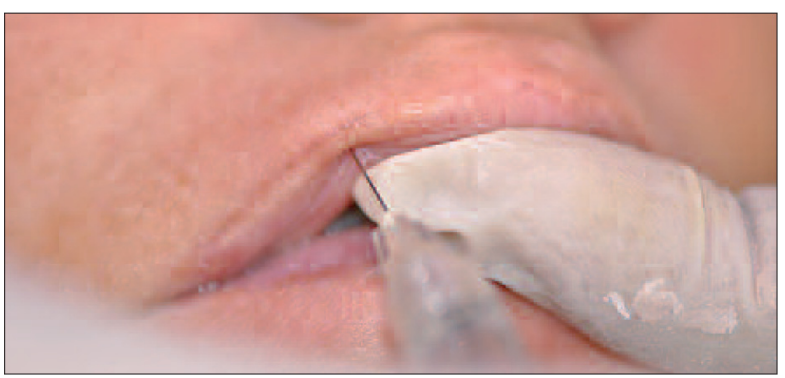

Figure 9

Second injection equidistant commissure-philtrum.
The first hyaluronic acid gels were particulate and because of this, they could migrate from the areas where they were injected. The consistency was granular. Today, we have gels with a smooth consistency allowing for more fluid and easier injections with longer lasting results.

Hyaluronic acid is considered a medical device since it works by mechanical action (friction from facial movements), whereas a medication works by pharmacological, metabolical, and immunological action.

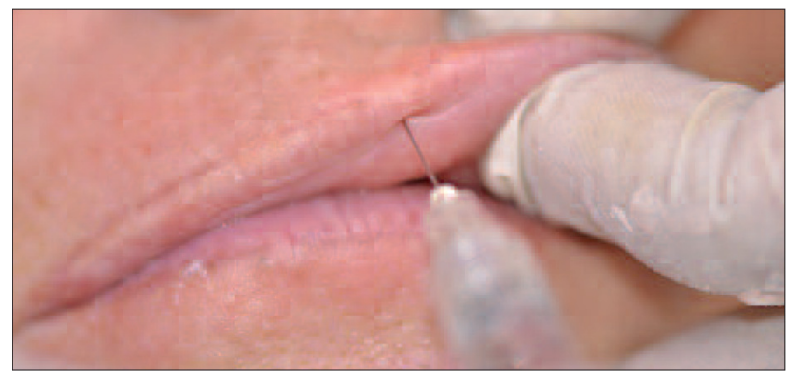

Figure 8

First injection in the center of the philtrum.

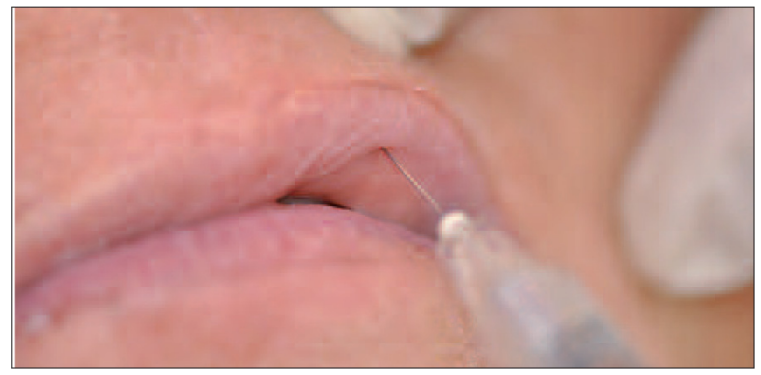

Figure 10

Repeat these two injections contralaterally. 
Because of this, hyaluronic acid does not require a marketing authorization (MA) but only a simple CE marking delivered by a nearby branch of French Health Products Safety Agency (AFSSAPS). The use of any medical device is authorized in the context of our practice.

\section{5 - FACIAL ANATOMY REVISITED}

It is essential for practitioners to have a solid grasp of the anatomy of the muscles, fat layers, nerves and vessels before they administer injections of hyaluronic acid.

It is also important to correlate modifications of dosage and the basic stigmas of skin ageing in order to regulate the dosage.

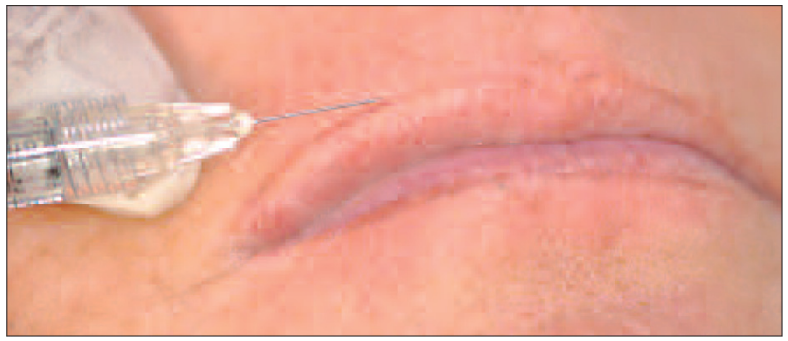

Figure 12

Insertion of the needle.

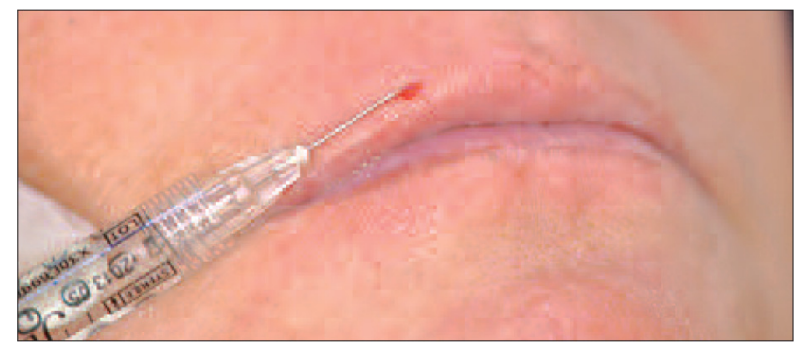

Figure 14

Length of the $2^{\text {nd }}$ point.

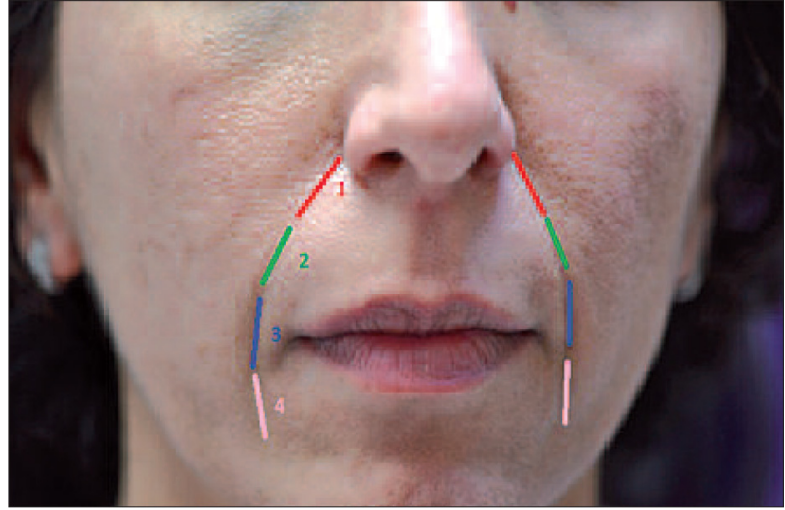

Figure 11

Retrograde linear threading injection points to treat the naso-labial folds.

- in red: $1^{\text {st }}$ linear threading injection,

- in green : $2^{\text {nd }}$ linear threading injection,

- in blue : $3^{\text {rd }}$ linear threading injection,

- in pink : $4^{\text {th }}$ linear threading injection.

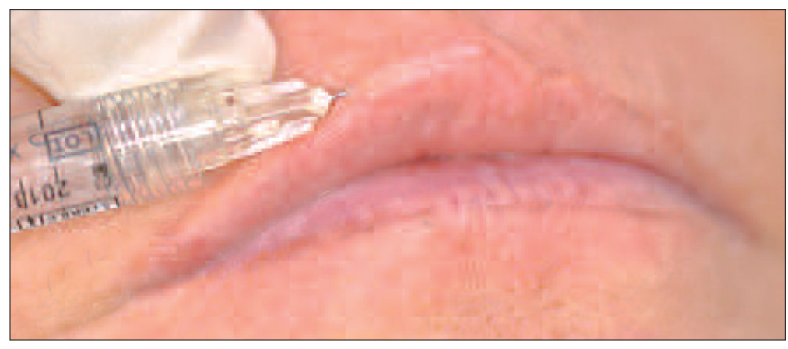

Figure 13

Retrograde linear threading injection.

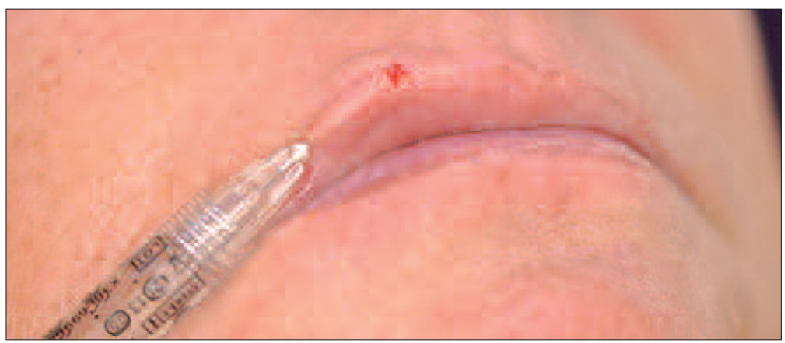

Figure 15

Retrograde linear threading injection. 


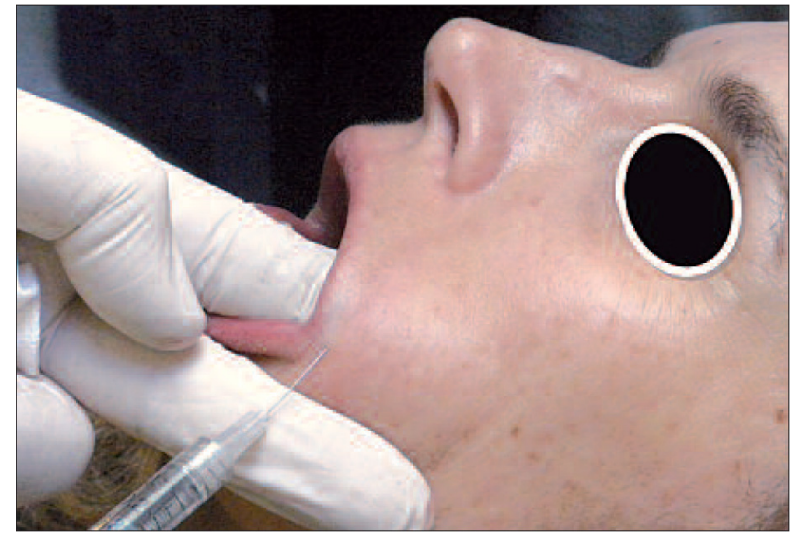

Figure 16

Injection with a cannula.

The facial muscles underly and support the tissues of the mouth and associated areas. They weave a veritable mesh under the dermis and continue along adjacent muscles. They have a fixed osseous insertion as well as a mobile cutaneous insertion; when they surround an orifice, they have a dilating or constricting action.

There are only two facial muscles without an osseous insertion: they are part of the superficial musculo-aponevrotic system (SMAS); the risorius muscle and the platysma muscle are responsible for the signs of ageing because of the shortening of the platysmal chords in the region of the neck.

Finally, it is important to understand the physiology of ageing. As we age, the muscles shorten and send deep fat pads to the facial surface. This fat, under the influence of gravity, has a tendency to sag, and over the years, results in loss of the oval visage as well as skeletalization.

\section{6 - DIFFERENT TECHNIQUES FOR ADMINISTERING INJECTIONS}

Three main techniques for administering injections can be combined: serial puncture, retrograde linear threading and with a cannula.
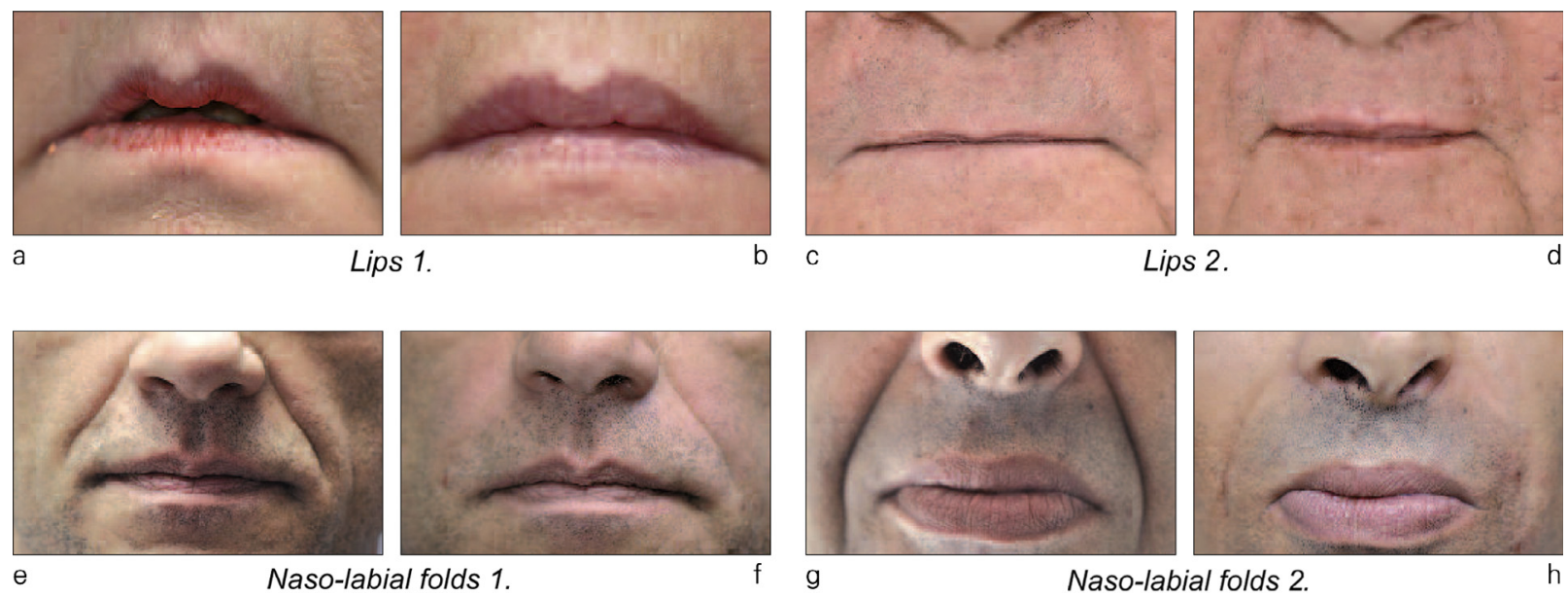

Figures 17a to 17h

Results "Before - After". 


\section{6- 1 - Injection by multi-puncture}

Several contiguous intradermal needle punctures must be made along the naso-labial fold.

By using this technique and making three needle punctures, at the center of the orbicularis muscle of the lips and at junction of the mucous membrane and in the keratinized tissue of the lip, the dentist can restore the volume of the lip.

\section{6- 2 - Retrograde linear threading injections}

In this type of injection, the dentist inserts the needle up to the guard at an angle of approximately $20^{\circ}$ to the plane of the epidermis, then once the needle is in, the hyaluronic acid is slowly injected while the needle is withdrawn.

Step by step, the whole area is treated.

This technique will allow us to redraw the border of the lip by making contiguous retrograde linear threading injections along the whole periphery of the lips.

\section{7 - CONCLUSION}

Hyaluronic acid not ony allows dentists to treat morphological anomalies related to ageing, but also to correct resorptions of the alveolar processes in order to perfect prosthetic procedures. Since the emergence of implantology, in many cases dentists have been able to provide patients with complete implant-

\section{6 - 3 Injection with a cannula}

This technique, which was introduced approximately 3 years ago, makes it possible to treat the nasolabial folds and other areas by using a flexible blunt-tipped cannula that looks like needles used for injection of a standard inferior aveolar nerve block.

It is painless, and by using a single puncture site, it is possible to treat all areas of the face that the dentists deal with, namely: the naso-labial folds, the upper and lower red lip, its border, the upper and lower white lip, and the marionette lines.

Injection with a cannula is infinitely less traumatic than the needle technique because a cannula is blunt-tipped and consequently cannot break the path of an artery and cause bruising or a hemotoma.

There is a single puncture site: it extends one centimeter beyond the commissure of the lips.

The principal advantage of this technique is that it produces very few hematomas and bruises.

supported bridges, instead of extracting all their remaining teeth and making full dentures for them.

In fact, when dentists made full dentures, we had to spend a lot of time adjusting the buccal wax rim which supports the lip; from now on, we can use hyaluronic acid to correct 
the volume of the soft tissues when transitioning to a fixed bridge.

Understanding the ageing process is essential when beginning the process of rehabilitating soft tissues.

By doing a complete analysis of patients, listening to their concerns, and performing their intra-oral examinations, we can choose the filler product best suited for their case.

This type of collaboration with our patients will ensure that therapeutic treatment will be successful.

\section{REFERENCE WORKS}

Baspeyras M. Législation des techniques de comblement des rides et de la toxine botulique en 2007. Cours pour le DU de techniques d'injection et de comblement. Paris : 10 mai 2007.

Flageul G, Godefroy M, Lacoeuilhe G. La fonction thérapeutique de la chirurgie esthétique. Ann Chir Plast Esthet 2003;48:247-56.

Hascall VJ, Laurent TC. Hyaluronan: structure and physical properties. http:// www.glycoforum.qr.jp/science/hyaluronan/HA01/HA01E.html

Inoue S. Skin hyaluronan: its metabolism and roles in skin physiology. Connect Tissue 2001;33:235-43.

Kamara F. La prévention du risque juridique. IMCAS (Paris) : Janvier 2004.

Penneau J. La responsabilité du médecin. Connaissance du droit. $3^{\mathrm{e}}$ ed. Paris : Dalloz, 2004.

Pons-Guiraud A, Bui P. L'art du comblement et de la volumétrie en esthétique. Rueil Malmaison : Arnette Edition, Coll. Dermatologie esthétique, 2009.

Salama JP. Une molécule pas comme les autres : I'acide hyaluronique. Dental Tribune. Esthétique tribune, édition française $2011 ; 3(12): 26$.

Sargos P. Le devoir d'information du médecin dans la jurisprudence de la cour de cassation. Ann Chir Plast Esthet 1998;43:668-73.

Wang F, Garza LA, Kang S, Varani J, Orringer JS, Fisher G, et al. In vivo stimulation of de novo collagen production caused by cross-linked hyaluronic acid dermal filler injections in phtodamaged human skin. Arch Dermatol 2007;143:155-63.

Zbili M. Classification des lèvres et protocoles thérapeutiques : expérience personnelle avec le Juvederm. J Med Esth Chir Dermatol. 2004 mars;XXXI(121):17-24.

\section{WEBSITE REFERENCED}

- http://www.ordre-chirurgiens-dentistes.fr/uploads/media/Lettre_ministere_acide_ hyaluronique.pdf 